\section{Commentary: First seek to understand (the database)}

\author{
Felix G. Fernandez, MD, MSc
}

An essential part of designing an observational research study or understanding database studies is understanding the strengths and limitations of the data source. Kidane and colleagues ${ }^{1}$ provide a detailed review of select databases that are used for large observational research studies in thoracic surgery. The authors clearly convey the specifications of each database they review for the benefit of outcomes researchers.

Administrative and clinical databases can be distinguished based on the purpose for which the data are collected. Administrative data are collected primarily for claim, billing, and discharge purposes. They are available at different levels, including national, state, hospital, or by specific payer. The data are organized in a uniform format that contains patient demographic characteristics, discharge status, diagnosis and procedure codes, and hospital identifiers. Examples include Centers for Medicare and Medicaid Services and Healthcare Cost and Utilization Project data. A clinic database, or patient registry, is "an organized system that uses observational study methods to collect uniform data (clinical and other) to evaluate specified outcomes for a population defined by a particular disease, condition, or exposure, and that serves a predetermined scientific, clinical, or policy purpose(s)." ${ }^{2}$ The majority of the databases described in this review (American College of Surgeons National Surgical Quality Improvement Project, Society of Thoracic Surgeons General Thoracic Surgery Database, and European Society of Thoracic Surgeons Database), all fall under the category of clinical registries. On the other hand, the databases from Denmark and Canada are administrative data sources.

From the Division of Cardiothoracic Surgery, Emory University School of Medicine, Atlanta, Ga.

Disclosures: The author reported no conflicts of interest.

The Journal policy requires editors and reviewers to disclose conflicts of interest and to decline handling or reviewing manuscripts for which they may have a conflict of interest. The editors and reviewers of this article have no conflicts of interest.

Received for publication March 26, 2021; revisions received March 26, 2021; accepted for publication March 29, 2021; available ahead of print April 2, 2021.

Address for reprints: Felix G. Fernandez, MD, MSc, Division of Cardiothoracic Surgery, The Emory Clinic, 1365 Clifton Rd, NE, Suite A2214, Atlanta, GA 30322 (E-mail: felix.fernandez@emoryhealthcare.org).

J Thorac Cardiovasc Surg 2021;162:1154-5

$0022-5223 / \$ 36.00$

Copyright (c) 2021 by The American Association for Thoracic Surgery

https://doi.org/10.1016/j.jtcvs.2021.03.093

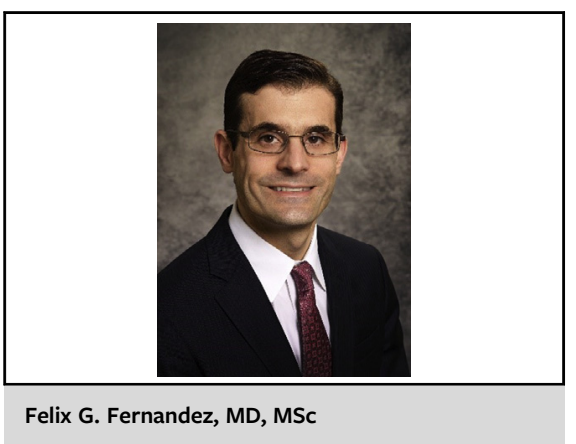

CENTRAL MESSAGE

Strengths and limitations of administrative and clinical data-

bases must be understood

before designing a research study.

Because of their differences, administrative and clinical data have distinct strengths and limitations in observational research. Advantages of administrative data are that they are population-based, readily available, generally inexpensive, and can provide a large sample size. However, weaknesses include limited information on clinical outcomes and details, frequent coding errors, and time lags in availability. Clinical database generally contain granular clinical detail. Therefore, these databases are most useful for analyzing a specific research question for the population for which they were initially designed. For example, the General Thoracic Surgery Database is well suited to examine operative risk in lung cancer surgery. Limitations of clinical data may include a lack of standardized data elements, difficulty in assessing trends in care, and lack of control groups.

Based on the reason for their creation and resultant strengths and limitations, administrative and clinical databases are best suited for different types of research studies. Appropriate use of administrative data include studies that examine utilization of surgery, real world outcomes such as volume-outcome relationships, and influence of policy changes. Clinical databases are best used for risk factor calculation, subset and rare outcomes analyses, and comparative effectiveness studies that generate hypotheses, determine sample size, or provide external validity for randomized controlled trials. It is clear to see that successful outcomes researchers will first seek to understand the databases available to best select the 1 that is most appropriate for testing the hypothesis in question. 


\section{References}

1. Kidane B, Wakeam E, Meguid RA, Odell DD. Administrative and clinical databases: general thoracic surgery perspective on approaches and pitfalls. J Thorac Cardiovasc Surg. 2021;162:1146-53.
2. Gliklich RE, Dreyer NA. Registries for evaluating patient outcomes: a user's guide. AHRQ publication No. 07-EHC001. Available at: https:// effectivehealthcare.ahrq.gov/products/registries-guide/research. Accessed April 6, 2021.
See Article page 1146.

\section{Commentary: Beyond the scope of randomized controlled trials: Navigating the sea of big data}

\author{
Alexandra L. Potter and Chi-Fu Jeffrey Yang, MD
}

Researchers in North America and Europe are increasingly using clinical and administrative databases to answer a wide range of research questions, from assessing the efficacy, cost, and complications of interventions to studying rare diseases. ${ }^{1-3}$ In addition, large-scale databases are a key resource for quality-improvement and have been used to inform quality measures for general thoracic and cardiac operations. ${ }^{4,5}$ While randomized controlled clinical trials (RCTs) are the gold standard for assessing the efficacy of interventions, studies using large-scale databases can complement the results of RCTs. Large clinical registries and administrative databases typically allow for analyses of sample sizes orders of magnitude larger than those of RCTs. Notably, the sizes of the available patient populations studied provide unprecedented statistical power to researchers and enable the performance of clinically meaningful subset analyses that would be difficult to do with RCTs. In addition, analyses of large-scale databases can allow for the study of rare diseases, uncommon clinical scenarios, and infrequently performed procedures. Of note, because analyses of large databases have data from realworld clinical practice, their results can be more generalizable than specialized single-institution studies or even an

\footnotetext{
From the Division of Thoracic Surgery, Department of Surgery, Massachusetts General Hospital, Boston, Mass.

Disclosures: The authors reported no conflicts of interest.

The Journal policy requires editors and reviewers to disclose conflicts of interest and to decline handling or reviewing manuscripts for which they may have a conflict of interest. The editors and reviewers of this article have no conflicts of interest.

Received for publication March 30, 2021; revisions received March 30, 2021; accepted for publication March 31, 2021; available ahead of print April 20, 2021.

Address for reprints: Chi-Fu Jeffrey Yang, MD, Division of Thoracic Surgery, Massachusetts General Hospital, 55 Fruit St, Boston, MA 02114 (E-mail: cjyang@ mgh.harvard.edu).

J Thorac Cardiovasc Surg 2021;162:1155-6

$0022-5223 / \$ 36.00$

Copyright (c) 2021 by The American Association for Thoracic Surgery

https://doi.org/10.1016/j.jtcvs.2021.03.111
}

Check for updates

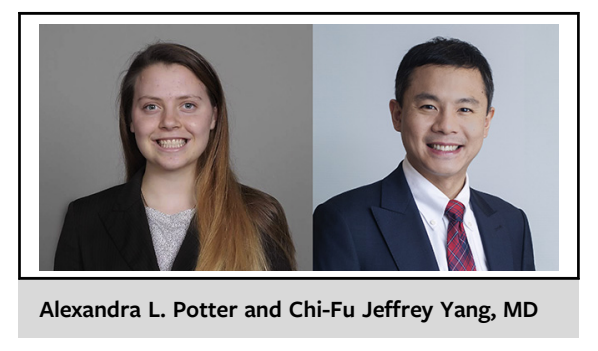

CENTRAL MESSAGE

In this editorial, Kidane and colleagues describe the strengths and limitations of commonly used databases and discuss how the construction and nature of each database influences its potential uses.

RCT, whose cohort may be healthier than the typical patient population. However, while large-scale databases provide many opportunities for well-designed and impactful studies, their potential uses must be mediated by a thorough understanding of their strengths and limitations.

In this issue of the Journal, the editorial by Kidane and Colleagues describes the strengths and limitations of several commonly used databases, including the American College of Surgeons National Surgical Quality Improvement Program (ACS NSQIP), Society of Thoracic Surgeons (STS) databases, European Society of Thoracic Surgeons (ESTS) database, and linked databases in Canada and Denmark. ${ }^{6}$ Of note, this editorial is a companion piece to a previous paper by Subramanian and colleagues ${ }^{7}$ that introduced the concept of clinical versus administrative databases and described other well-known databases such as the National Inpatient Sample, Surveillance, Epidemiology, and End Results database, and the National Cancer Database. In the present editorial, Kidane and Colleagues discuss the ways in which the construction and nature of each database influence its potential uses. Importantly, 